\title{
SOCIOECONOMIC DETERMINANTS OF RURAL HOUSEHOLDS' FOOD SECURITY STATUS IN NORTHERN GHANA
}

\author{
ANTWI, K.D. ${ }^{1}$ and. LYFORD, C.P ${ }^{2}$ \\ 1. CSIR-Science and Technology Policy Research Institute (STEPRI), P.O.BOX CT519 \\ Cantonments - Accra \\ 2. Texas Tech University, Box 42132. Lubbock, TX 79409.
}

\begin{abstract}
National aggregate data to analyze food security status at the national level has often been used in many countries including Ghana to determine food security status. This has been a reason that many interventions that have had minimum or no impact on households' food security status due to variation within region in the design of such interventions. This study used household level-data data from 2260 rural households to determine rural household food insecurity status, and also identify and analyze the socioeconomic factors that significantly influence rural household level food insecurity. The study used the Food Consumption Score (FCS) as the index for household food security status. An ordinal logit model was used to predict household food security status with respect to twelve explanatory variables. The results showed that $70 \%$ of the sampled rural households were food insecure, and in particular, food insecurity was found to be more pronounced among female-headed households. The results further showed that improved education, increased household income, improved access to agricultural credit and large farm size increase the probability of households to attain high food security status. On the other hand, high food prices and large household size were found to reduce the probability of households to attain high food security status. For policy implication, these micro-level factors need to be considered in the implementation of food insecurity interventions programs in order to achieve desired outcomes.
\end{abstract}

Key Words: Food Security, Food Consumption Score, Rural Households, Ordinal logit

https://dx.doi.org/10.4314/jafs.v19i2.9

\section{INTRODUCTION}

According to the World Bank, Ghana has seen a steady economic growth over the past decade (World Bank, 2014). Despite this economic growth, food insecurity is still evident and remains a challenge particularly among rural households in Ghana. According to the Ghana Statistical Service (GSS), food insecurity and malnutrition are more severe in the rural areas of Northern Ghana (GSS, 2010). The conditions of food insecurity and malnutrition is a characteristic of many developing countries, and according to the Food and Agricultural Organization (FAO), the number of people in the world who are undernourished has increased to about 820 million people in the world are still hungry today, underscoring the immense challenge of achieving the Zero Hunger target by 2030, and about 2 billion people in the world experience moderate or severe food insecurity (FAO 2019). The worrying conditions of food insecurity and malnutrition in Northern Ghana are one of the justifications for the implementation of government's policy intervention programs that are targeted at improving food security (MoFA, 2010).

These intervention programs should not be implemented in isolation but within the social, economic, cultural, and political setting or

Journal of the Faculty of Agriculture and Veterinary Medicine, Imo State University Owerri website: www ajol.info 
space within which these interventions are implemented. Consequently, the success or failure of these intervention programs are influenced by social, cultural, economic, and demographic characteristics of the target population (Pieters et al, 2013). From a food security policy perspective, it is essential to understand these factors that influence food security at the household level. A better understanding of the cultural, social, and economic factors is significant to the design of policies and their implementation to achieve maximum impact with regards to rural household food security status. To identify and analyze these socioeconomic factors, previous studies including (Adom, 2014) have been carried out in Ghana using national aggregated data and results of these studies have been reported on an aggregate basis. However, as noted by the FAO high food security status at the global or national level does not guarantee high food security status at the household level (FAO, 2009). Motivated by the need to understand the dynamics of food insecurity at the household level using household micro-level data, this research was conducted to generally identify and analyze the factors that predict household food security status. Specifically, this study was conducted to determine food security status of rural households, and also to analyze the significant socioeconomic predictors of rural household food security status in Northern Ghana.

\section{Materials and Methods}

This study used data collected by the USAIDFeed The Future Program from 2260 rural households in the Northern Region of Ghana. Supplementary data, particularly on retail prices of food commodities from the Ghana Ministry of Food and Agriculture in the Northern Region were also used. Food prices data were regional average monthly retail food prices for the various major food commodities in northern Ghana. In all, fiftyeight food commodities were used to calculate average food prices. These individual prices were weighted by the respective geometric mean of the food commodity to compute the aggregate commodity prices using the Laspeyres price index. The computed aggregate commodity prices were used as one of the explanatory variables in the empirical model.

\section{Determining Household Food Security Status}

Food Consumption Score (FCS) was used as the measure of food security and is an index for household food security status (Maxwell et al, 2013). FCS was used for this study because the data captured household level food consumption based on a 7-day recall. Further, this metric has been widely used by researchers and practitioners in developing countries for assessing food security at the household level. Following Maxwell et al (2013), appropriate thresholds were used to recode the food consumption score variable from a continuous variable to a categorical variable. Following FAO (2009), we classified a household as having poor food security status if its FCS is between 0 and 21, being on a borderline if its FCS is between 21.5 and 35, and having acceptable food security status if its FCS is greater than 35 .

\section{Analytical Estimation}

For this study, we specified the ordinal logit model to determine the effects of a number of social, economic and demographic characteristics of the households that could predict their food security status. This estimation procedure was used because the dependent variable has more than two ordered categories and also, this estimation procedure allows for predicting the effect of a change in any of the explanatory variable on the categorical dependent variable (Cameron and Travedi, 2009). The ordinal logistic model with a single latent variable $y_{i}$ according to Cameron and Travedi (2009) is given as:

\section{Journal of the Faculty of Agriculture and Veterinary Medicine, Imo State University Owerri} website: www ajol.info 


$$
\begin{aligned}
& y_{i}=x_{i}^{\prime} \beta+\mu i \\
& \qquad y_{i}=j \text { if } \alpha_{j-1}<y_{i}^{*} \leq \alpha_{j}
\end{aligned}
$$

The probability that observation $i$ will belong to alternative $j$ is given as:

$$
\begin{aligned}
p_{i j}=p\left(y_{i}\right. & =j)=p\left(\alpha_{j-1}<y_{i}^{*} \leq \alpha\right)=F\left(\alpha_{j}-x i^{\prime} \beta\right) \\
& -F\left(\alpha_{j-1}-x i^{\prime} \beta\right)
\end{aligned}
$$

where $F$ is the logistic $\operatorname{CDF} F(z)=\frac{e^{z}}{\left(1+e^{z}\right)}$

The marginal effects of the probabilities:

$$
\frac{d \operatorname{Pr}\left[y_{i}=j\right]}{d x_{i}}=\left\{F^{\prime}\left(\alpha_{j-1}-x i^{\prime} \beta\right)-F\left(\alpha_{j}-x i^{\prime} \beta\right)\right\} \beta
$$

Where $F^{\prime}$ is a derivative of $F$. The sum of the marginal effects is assumed to be equal to zero since a given household can only belong to a particular category at any point in time.

\section{Empirical Analysis}

The data for this study were analyzed in two stages. In the first stage, the household food security status was determined and households were categorized using the derived household FCS values. The difference in food security status based on sex of the household head was also analyzed. The second stage involved the ordinal logistic analysis which allowed for the analysis of the predictors of rural household food security. The marginal effect of each explanatory variable was calculated to explain the effect of a change in each of the explanatory variable on the dependent variable.

Based on the data available, we used a vector of explanatory variables including age of household head, sex of household head, marital status of household head, educational level of household head, household size, household monthly food expenditure, retail food prices, household access to agricultural

credit facility, household farm/plot size, and interaction terms involving sex of household head and income, sex of household head and education, and sex of household head and farm/plot size. We used these interactive terms to understand how female headed household would be affected by changes in any of the interactive variables.

\section{Results and Discussion}

The results show an average age of 37 years (SD =17.7) indicating a relatively young population as shown in Table 1. A young population provides the opportunity for agriculture and market through the provision of labour force from whom countries can increase their tax revenues (Srinivasan, 2010). The results in Table 1 further show that basic level education is the most common education attainment in the study area with 4.1years as the average years of attainment. This low level of education found corroborates the 2010 report of the Ghana Population and Housing Census which indicates that the Northern Region of Ghana has less than 20\% of the population from 11 years and older have attained secondary and tertiary education (GSS, 2010). The results further show relatively large household size with an average of 5.6 persons/household $(\mathrm{SD}=1.61)$ and which is higher than the national average of 4.4 persons/household.

The results in Table 2 shows that more than half $(70 \%)$ of the total households are highly food insecure, about $17 \%$ are moderately food insecure and $13 \%$ are food secure. This result indicates high-level food insecurity among the study population. Table 3 also shows that food insecurity is higher among female-headed households as compared to male-headed households. Within the femaleheaded households, about $71 \%$ fall within the high food insecurity category status as compared to $67 \%$ of male-headed households in that category. Many factors including minimal level of education, limited access to

\section{Journal of the Faculty of Agriculture and Veterinary Medicine, Imo State University Owerri} website: www ajol.info 
land, limited access to produce markets, inadequate access to agricultural extension services, and restricted access to credit facilities to female farmers have been found by previous studies (SEND-Ghana, 2014).

Table 3 shows the ordered logit regression results of the factors that predict rural household food security in the northern region of Ghana. Since the likelihood ratio test statistics exceeds the chi-square critical value, the hypothesis that all coefficients in the model except the intercept are equal to zero is rejected $(\mathrm{LL}=-1897.07 ; \mathrm{Prob}>\mathrm{ChiSq}=41.56$ (0.0023). The coefficient of age was found to be positive among the sample household at $10 \%$ significance level. This suggests that as household heads advance in age, their food security status increases. A unit increase in the age of household head increases the probability of a household to be food secure by 0.07 . This result is consistent with previous authors such as Aidoo et al., (2013) and Bawadi et al (2012) who found that increase in age of household head increases the probability of a household to be food secure.

The results show that female-headed households have a significantly reduced probability of attaining high food security status. The marginal effects suggests that the probability of a female-headed household to attain high food security status reduces by $5.8 \%$. A similar result was obtained by previous studies such as (Gabrehiwot and van der Veen, 2014) and (Aidoo et al., 2013).

Educational level of the household head was found to have a positive and significant influence on the probability of household to attain high food security status. A unit increase in the level of education of a household head increases the probability to be food secure by $5.4 \%$. In the context of urban households, the study found education is a key determinant with respect to food production, food access, and food utilization Journal of the Faculty of Agriculture and Veterinary Medicine, Imo State University Owerri website: www ajol.info as was also found by (Mkhawani et al., 2016). In addition, education is linked to better career prospects that offer individuals and households with the knowledge of how to address the nutritional requirements of their family members. Similar results were obtained by previous studies including Bogale and Shimelis (2009) and Jayne et al., (2015).

An increase in household size was found to reduce the probability of a household to attain high food security status. This result suggests that a unit increase in household sizes reduces the probability of the household to attain high food security status by $3.4 \%$. Under a condition of large family size (average of 5.6), household demand for food is likely to increase, and in an area such as the study area where farm average size ( 1.65 acres) has been found to be small, household food demand is expected to outweigh household food supply. This result is found to be consistent with a study by (Habyarimana, 2015) who found that households with large family size have a high probability to be food insecure than those with lower family size.

The results in Table 3 further show that an increase in household income increases the probability of a household to attain high food secure status by $5.3 \%$ as a result of a unit increase in household income. Previous studies which found similar results such as Bawadi et al., (2012) and Rehm et al., (2011) explained that household expenditure on vegetables and fruits, which improve dietary diversity increases as household income increases. Conversely, this study found that household monthly income in the northern region of Ghana (GHC $210.00 \equiv \$ 38$ ) is lower compared to the national average (GHC $860.00 \equiv \$ 156)$ and contributed to the high incidence of poverty in the region.

As expected, the results show an inverse relationship between high food prices and the probability of households to attain high food security status. A unit increase in the retail 
Volume 19, Number 2, October 2021, pp $86-94$

price of food commodities reduces the probability of a household to achieve high food security status by $9.4 \%$. Previous studies found that the quality of diet is affected by a rise in food prices and that higher dietary quality is associated with higher dietary cost (Mkhawani et al., 2016). Rising food prices have also been found to negatively affect purchasing and eating characteristics of the rural poor (Mutisya et al., 2016). These rural households in the study area are typically net food consumers' despite being food producers and thus, suffer from high food insecurity in the event of rising food prices. As local food price increases, a potential solution is for policymakers to implement policies such as cash transfers and school feeding programs for children in affected communities that protect rural households from the negative effect of increased food prices.

The results of the study in Table 1 show that there is a high probability for female-headed households to attain relatively higher food security status if they have high incomes, improved access to credit, as well as increased level of education, as explained by the interactive terms in the model. This suggests that female-headed households would achieve relatively greater success of in improving their food security status if access to credit, education, and income were improved.

\section{Summary and Conclusion}

The findings of this study provide evidence that food insecurity continues to be commonplace with many rural households in northern Ghana. Study results show that rural households' food security status is negatively influenced by factors including gender of the household head, food prices, and household size. The study has further shown that factors including improved educational level of the household head, improved household access to agricultural credit, and increased household income improve rural households' food security status. Nevertheless, the level of education, access to agricultural credit facilities, and household income in the region are lower than national averages. It has been established that females play important role in feeding the world and ensuring household food security. In view of these critical role, it is imperative that these barriers are removed to enable female farmers play these roles effectively to achieve food security at the household level.

The study revealed female-headed households in rural northern Ghana are significantly more likely to be food insecure than male-headed households in the study area. The study has further shown that women are disadvantaged in access to credit to women, education, and land access to land with further impacts on their food security status. A particularly relevant approach would be to develop policies and programs that seek to improve these among women to unearth the potentials of women and improve food security.

This study has identified specific socioeconomic factors that influence food insecurity of households in rural areas of northern Ghana, and these factors need to be considered for maximum outcomes of intervention programs. Food security interventions can use these results in the effective design and implementation of effective measures to reduce household food insecurity in the region.

\section{Journal of the Faculty of Agriculture and Veterinary Medicine, Imo State University Owerri} website: www ajol.info 
Volume 19, Number 2, October 2021, pp 86 -94

\section{REFERENCES}

Adom, K.P. (2014). Determinants of Food Availability and Access in Ghana. Studies in Agricultural Economics 2(1): 23-31.

Aidoo, R.,Mensah, J.O.\&Tuffour, T. (2013). Determinants of food security in the Sekyer-Afram Plains District of Ghana. European Scientific Journal 9(21):514521.

Bawadi, H.A.,Tayyem, R.F., Dwairy, A.N., \&Al-AkourN (2012). Prevalence of Food Insecurity among Women in Northern Jordan. Journal of Health Population Nutrition 30(1): 49-55.

Bogale, A. \& Shimelis A. (2009). Household Level Determinants of Food Insecurity in Rural Areas of Dire Dawa, Eastern Ethiopia. African Journal of Food, Agriculture, Nutrition and Development 9(9):1914-1926.

Cameron, A.C.\&Trivedi, T.K. (2005). Microeconometrics-Methods and Applications. New York: Cambridge University Press. 2005.

FAO (2009).The State of Food Insecurity in the World: Economic Crises-Impacts and Lessons Learned. Rome: FAO. 2009.

FAO (2019).The State of Food Insecurity in the World: Meeting the 2015 International Hunger Targets: Safeguarding Against Economic Slowdowns and Downturns. Rome: FAO 2019.

Gabrehiwot, T.\& van der VeenA (2014). Estimating the Impact of Food Security Program by Propensity-Score Matching. Journal of Development and Agricultural Economics7(1):38-47.

Ghana Statistical Service (2010). Ghana Poverty Mapping. Accra-Ghana: Ghana Statistical Service. 2015.
Ghana Statisitical Service (2010). National Population and Housing Census. AccraGhana: Ghana Statistical Service 2010.

Habyarimana, J.B. (2015). Determinants of Household Food Insecurity in Developing Countries; Evidence from a Probit Model for the Case of Rural Households in Rwanda. Sustainable Agriculture Research 4(2):78-91.

Jayne, M., Myers, F.\&Matha, B. (2003). Smallholder Income and Land Distribution in Africa. Food Policy (2):253-275.

Maxwell D., Jennifer, C.\&Bapu B. (2013). How Do Different Indicators of Household Food Security Compare? Empirical Evidence from Tigray. Medford, USA: Feinstein International Center, Tuft University. 2013.

Mkhawani, K., Motadi, S.A., Mabapa, N.S.\&NbhenyaneX.G. (2016). Effects of Rising Food Prices on Household Food Security among Female-headed Households in Runnymede Village, Mopani District, South Africa. South African Journal of Clinical Nutrition 29(2):69-74.

MoFA (2010).Food and Agricultural Sector Development Policy II (FASDEP II). Accra, Ghana: MoFA. 2010.

Mutisya, M., Ngware, M.W., Kabiru, C.W.\&Ngianga-Bakwin, K. (2016). The Effect of Education on Household Food Security in Two Informal Urban Settlements in Kenya: A Longitudinal Analysis. Food Security8:743-756.

Pieters, H., Guaison, A.\& VandeplasA. (2013). Conceptual Framework for the Analysis of the Determinants of Food and Nutrition Security. KU Leuven, Belgium: Foodsecure, 1 (3): 3153-164.

Rehm, C.D., Monsivals, P.\&Dreewnowski, P. (2011). The Quality and Monetary

Journal of the Faculty of Agriculture and Veterinary Medicine, Imo State University Owerri website: www ajol.info 
Journal of Agriculture and Food Sciences

Volume 19, Number 2, October 2021, pp $86-94$

Value of Diets Consumed by Adults in the

United States. American Journal of

Clinical Nutrition, 94:1333-1339.

World Bank Group (2014).Global Economic Prospects Forcast for Ghana. Washington DC: The World Bank.

SEND-Ghana (2014).Women and

Smallholder Agriculture in Ghana. Accra, Ghana: SEND-Ghana. 2014.

Srinivasan. K. (2010).Advantages of a Youthful Population in LEDCs. AP/IB

Zakaria, S., Ying, L. \& Baohui, S (2014). Factors Influencing Household Food Security in West Africa: The case of Southern Niger. Sustainability 6 (1):11911202 .

Geography.

Journal of the Faculty of Agriculture and Veterinary Medicine, Imo State University Owerri website: www ajol.info 
Journal of Agriculture and Food Sciences

Volume 19, Number 2, October 2021, pp $86-94$

\section{APPENDIX}

Table 1: Summary Statistics

\begin{tabular}{|c|c|c|c|c|}
\hline Variable & Mean & $\begin{array}{c}\text { Std. } \\
\text { Deviation }\end{array}$ & Minimum & Maximum \\
\hline Age of household head (years) & 37.00 & 17.72 & 21 & 76 \\
\hline $\begin{array}{l}\text { Educational level of household head } \\
\text { (years) }\end{array}$ & 4.18 & 2.21 & 0 & 7 \\
\hline Household Size (number) & 5.59 & 1.61 & 3 & 9 \\
\hline Marital Status of household head & 0.54 & 0.46 & 0 & 1 \\
\hline Farm size of household (acre) & 1.65 & 0.59 & 1 & 5 \\
\hline $\begin{array}{l}\text { Total household monthly Income } \\
(\mathrm{GH} \phi)\end{array}$ & 210.75 & 2.08 & 67.00 & 264.00 \\
\hline $\begin{array}{l}\text { Total household monthly food prices } \\
(\mathrm{GH} \phi)\end{array}$ & 450.00 & 3.13 & 102.00 & 495.00 \\
\hline Access to credit ( $0=$ otherwise, $1=y e s)$ & 0.47 & 0.30 & 0 & 1 \\
\hline $\begin{array}{l}\text { Gender of household head } \\
(0=\text { otherwise, } 1=\text { female })\end{array}$ & 0.39 & 0.49 & 0 & 1 \\
\hline $\begin{array}{l}\text { Marital status of household head } \\
(0=\text { otherwise, } 1=\text { unmarried })\end{array}$ & 0.52 & 0.45 & 0 & 1 \\
\hline Food Consumption Score & 18.58 & 8.08 & 12 & 41 \\
\hline
\end{tabular}

Table 2: Food Security Status of Sampled Households

\begin{tabular}{lccc}
\hline & $\begin{array}{c}\text { Low Food } \\
\text { Security Status }\end{array}$ & $\begin{array}{c}\text { Medium Food } \\
\text { Security Status }\end{array}$ & $\begin{array}{c}\text { High Food } \\
\text { Security Status }\end{array}$ \\
\hline $\begin{array}{l}\text { Food Consumption Score } \\
\text { Category }\end{array}$ & 0 & 1 & 2 \\
$\begin{array}{l}\text { Number of households } \\
\text { (Frequency) }\end{array}$ & 1579 & 391 & 294 \\
Percentage & 69.88 & 17.30 & 13.02 \\
\hline
\end{tabular}

Journal of the Faculty of Agriculture and Veterinary Medicine, Imo State University Owerri website: www ajol.info 
Journal of Agriculture and Food Sciences

Antwi , K.D. and Lyford, C.P. 94

Volume 19, Number 2, October 2021, pp 86 - 94

Table 3: Food Security Status of Male-headed and Female-headed Households

\begin{tabular}{ccc}
\hline Food Security Status Category & \multicolumn{3}{c}{ Household Type } \\
& $\begin{array}{c}\text { Male-Headed Households } \\
(\mathrm{N}=1388)\end{array}$ & $\begin{array}{c}\text { Female-Headed Households } \\
(\mathrm{N}=872)\end{array}$ \\
\hline Low Food Security Status & 862 & 619 \\
Medium Food Security Status & 295 & 156 \\
High Food Security Status & 231 & 97 \\
\% LFS Status & 0.62 & 0.71 \\
\hline
\end{tabular}

Table 4: The maximum likelihood estimates of the ordered logit model

\begin{tabular}{|c|c|c|c|c|}
\hline Variable & Estimate & $\begin{array}{l}\text { Std. } \\
\text { Error }\end{array}$ & p-val & $\begin{array}{l}\text { Marginal } \\
\text { Effects }(\mathrm{dy} / \mathrm{dx})\end{array}$ \\
\hline Age of HH Head (years) & 0.03 & 0.017 & $0.070^{*}$ & 0.07 \\
\hline $\begin{array}{l}\text { Gender of } \mathrm{HH} \text { Head } \quad \text { (1=female, } \\
0=\text { otherwise })\end{array}$ & -0.48 & 0.279 & $0.085^{*}$ & -0.058 \\
\hline Marital Status $(1=$ married, $0=$ otherwise $)$ & 0.23 & 0.318 & 0.700 & 0.073 \\
\hline Education (years) & 0.053 & 0.015 & $0.000 * * *$ & 0.054 \\
\hline Household size (number) & -0.143 & 0.021 & $0.031 * *$ & -0.034 \\
\hline Household Monthly Income (GHC) & 0.053 & 0.014 & $0.047 * *$ & 0.035 \\
\hline Food Prices (GHC) & -0.024 & 0.018 & $0.063^{*}$ & -0.094 \\
\hline Access to credit ( $1=$ access, $0=$ otherwise $)$ & 0.281 & 0.321 & 0.267 & 0.027 \\
\hline Farm size (acre) & -0.058 & 0.298 & 0.844 & 0.052 \\
\hline Gender\&* Education & 0.213 & 0.051 & $0.027 * *$ & 0.069 \\
\hline Gender \& Income & 1.047 & 0.265 & $0.000 * * *$ & 0.052 \\
\hline Gender \& Credit & 0.616 & 0.261 & $0.018 * *$ & 0.069 \\
\hline $\begin{array}{l}\text { Gender \& Farm size } \\
\text { pseudo } \mathrm{R}^{2}=0.073 ; \mathrm{LL}=-1897.07 ; \text { Prob }>C \\
\mathrm{p}<0.01, * * \mathrm{p}<0.05, * \mathrm{p}<0.1\end{array}$ & $\begin{array}{l}0.312 \\
q=4\end{array}$ & $\begin{array}{l}0.401 \\
56 \quad(0.0\end{array}$ & $\begin{array}{c}0.892 \\
023) ; * * *\end{array}$ & 0.099 \\
\hline
\end{tabular}

Journal of the Faculty of Agriculture and Veterinary Medicine, Imo State University Owerri website: www ajol.info 